\title{
Influence of Deformation Controlled Strain Rate on Tensile and Compression Behaviour of Magnesium and Steel Wire
}

\author{
Thorsten Henseler ${ }^{1, a^{*}}$, Madlen Ullmann ${ }^{1, b}$, Grzegorz Korpala ${ }^{1, c}$, \\ Klaudia Klimaszewska ${ }^{2, \mathrm{~d}}$, Rudolf Kawalla ${ }^{1, \mathrm{e}}$ and Franz Berge ${ }^{1, \mathrm{f}^{\prime}}$ \\ ${ }^{1}$ Institute of Metal Forming, Bernhard-von-Cotta-Str. 4, 09599 Freiberg, \\ Technical University Bergakademie Freiberg, Germany \\ ${ }^{2}$ Czestochowa University of Technology, J. H. Dabrowskiego 69, 42-201 Czestochowa, Poland \\ athorsten.henseler@imf.tu-freiberg.de, ${ }^{b}$ madlen.ullmann@imf.tu-freiberg.de, \\ 'grzegorz.korpala@imf.tu-freiberg.de, ${ }^{\mathrm{c}}$ klaudia.klima93@gmail.com, \\ rudolf.kawalla@imf.tu-freiberg.de, ffranz.berge@imf.tu-freiberg.de
}

Keywords: strain rate, magnesium alloy, steel, yield stress, wire

\begin{abstract}
This article demonstrates the difference in the flow curves of an AZ31 magnesium alloy and S235JR structural steel wire caused by non-linear strain rates during uniaxial tensile and compression testing at elevated temperatures. Throughout tensile deformation, the traverse velocity of the testing machine has to be adapted according to the current elongation of the specimen, thus accelerating, to ensure a constant strain rate during the admission of the stress-strain curve. The equivalent is necessary during compression testing, where the traverse velocity of the testing machine needs to decelerate ensuring a constant strain rate. Nevertheless, tensile and compression tests are performed with constant traverse velocity, which lead to divergent flow curves in comparison to deformation controlled traverse velocities. The results of the research show the difference in flow behaviour of magnesium and steel wire, when the temperature and strain rate are varied in conjunction with constant and deformation controlled traverse velocities.
\end{abstract}

\section{Introduction}

Magnesium alloys have greatly gained stake in application fields of the automobile and aeronautical industry. Lightweight engineering has made magnesium alloys very sought-after. Most applications and scientific studies of magnesium wire are generally concerned with the biomedical use and lesser for the use as connecting element or electrical wiring [1-4]. Steel wire on the other hand is well established in all sorts of connecting elements and wire applications. The low-carbon steel grade S235JR is widely used in all sorts of engineering such as freight cars, dump trucks, machinery and piping. Both materials exhibit fundamentally different forming characteristics, which predominantly root in their lattice structure. The cubic lattice structure of steel changes from a body-centred (ferrite) to a face-centred (austenite) variation during heating. In opposition, magnesium has a hexagonal lattice structure, which leads to a significantly altered deformation mechanism behaviour.

The characterisation of mechanical and forming properties is commonly done in uniaxial tensile, compression or torsion tests. Flow curves, which are derived from the testing machine's measurements, are particularly important for the modelling and simulation of forming processes. Material specific parameters and coefficients need to be determined and influences, e.g. deformation temperature and strain rate, distinctively quantified. Therefore, reliable experimental data is needed and established through special experimental setups and control systems. Magnesium alloys and steel for example react to varying strain rates in a way, that high strain rates lead to higher yield stresses and vice versa [5-7]. Considering the influence of strain rates during tensile and compression testing, this article aims to clarify whether tests done with constant or deformation controlled traverse velocity have an impact on flow curves on the example of an AZ31 magnesium alloy and a carbon steel grade S235JR. 


\section{Materials and Experimental Procedure}

In the present work, extruded magnesium alloy AZ31 wire and hot rolled S235JR steel wire, both with an original diameter of $12 \mathrm{~mm}$, were studied. The materials were machined to standardised tensile test specimens, $10 \mathrm{~mm}$ in diameter and a gauge length of $20 \mathrm{~mm}$. Compression tests were conducted as well, because on the one hand higher strains can be achieved without necking in comparison to flow curves from tensile tests. On the other hand, anisotropic deformation behaviour is expected from the magnesium alloy. The reasoning lies in the directional dependence of deformation mechanisms in the hexagonal lattice structure, which is enhanced by the distinct texture leading back to the extrusion process $[8,9]$. Standardised compression test specimens were machined with a ratio of $10 \mathrm{~mm}$ in diameter to $18 \mathrm{~mm}$ in length to eliminate the risk of specimens buckling when tested. The chemical composition of the investigated materials is presented in Table 1.

Table 1: Nominal chemical composition of the tested magnesium alloy and carbon steel grade

\begin{tabular}{|c|c|c|c|c|c|c|c|c|c|}
\hline \multicolumn{10}{|c|}{ AZ31 [weight-\%] } \\
\hline $\mathrm{Al}$ & $\mathrm{Zn}$ & $\mathrm{Mn}$ & $\mathrm{Zr}$ & $\mathrm{Cu}$ & $\mathrm{Si}$ & $\mathrm{Fe}$ & $\mathrm{Ni}$ & $\mathrm{Ca}$ & $\mathrm{Mg}$ \\
\hline 3.29 & 1.33 & 0.472 & 0.00191 & 0.001 & 0.0196 & 0.0033 & 0.001 & 0.001 & balance \\
\hline \hline \multicolumn{10}{|c|}{ S235JR [weight-\%] } \\
\hline $\mathrm{C}$ & $\mathrm{Si}$ & $\mathrm{Mn}$ & $\mathrm{P}$ & $\mathrm{S}$ & $\mathrm{Cr}$ & $\mathrm{N}$ & $\mathrm{Al}$ & $\mathrm{Mo}$ & $\mathrm{Fe}$ \\
\hline 0.103 & 0.235 & 1.12 & 0.012 & 0.0084 & 0.061 & 0.014 & 0.027 & 0.0049 & balance \\
\hline
\end{tabular}

The tests were carried out at elevated temperatures on a Gleeble HDS-V40 testing machine with initial strain rates of $\dot{\varphi}_{0}=0.1 \mathrm{~s}^{-1}, 1 \mathrm{~s}^{-1}$ and $5 \mathrm{~s}^{-1}$. Due to the change in geometric relations of the lengthened or shortened specimen, the traverse velocity was controlled respectively during testing, just as explained introductorily. Throughout the tensile test, the traverse velocity was increased and during the compression test decreased resulting in constant strain rate until fracture. In comparison, tests with equal initial strain rate, but constant traverse velocities, as stated in Fig. 1, were carried out.

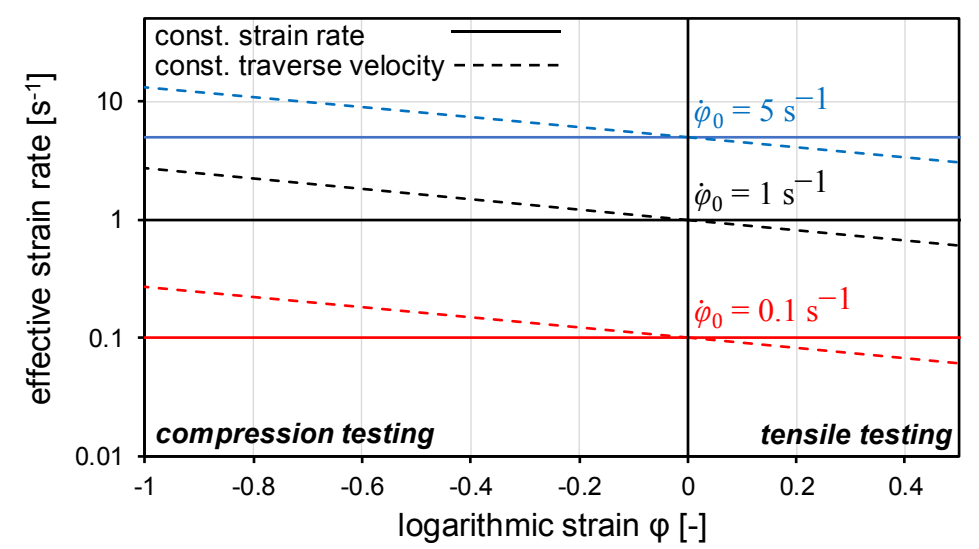

traverse velocity $v_{T}$ at $\varphi=0$ :

$$
\begin{aligned}
& v_{T\left(\dot{\varphi}_{0}=0.1 \mathrm{~s}^{-1}\right)} \approx 1.8 \mathrm{~mm} / \mathrm{s} \\
& v_{T\left(\dot{\varphi}_{0}=1 \mathrm{~s}^{-1}\right)} \approx 18 \mathrm{~mm} / \mathrm{s} \\
& v_{T\left(\dot{\varphi}_{0}=5 \mathrm{~s}^{-1}\right)} \approx 90 \mathrm{~mm} / \mathrm{s}
\end{aligned}
$$

Fig. 1. Theoretical deviation of effective strain rate from the initial strain rate with progressing deformation during testing due to constant traverse velocity

The loading direction was parallel to the extrusion or rolling direction at elevated temperatures of $250{ }^{\circ} \mathrm{C}$ and $350{ }^{\circ} \mathrm{C}$ for the magnesium alloy as well as $900{ }^{\circ} \mathrm{C}$ and $1000{ }^{\circ} \mathrm{C}$ for the steel grade, since these are within the range of most common processing temperatures. During conductive heating at a rate of $5 \mathrm{~K} / \mathrm{s}$ the temperature was controlled with a thermocouple, which was welded centrally on the specimens. Before loading the specimens where held at the testing temperature for $30 \mathrm{~s}$. After the tests, the compressed specimens were quenched in water, while the tension specimens where left to cool in the testing device. The scope of this research included the analysis of the microstructure with optical microscopy, as well. The flow curves were derived from the force-displacement and specimen temperature data recorded by the testing machine. Therefore, the 
yield stresses and corresponding true strains were calculated according to the von Mises yield criterion [10]. The falsifying influences of the generated heat through internal friction during deformation and friction between the specimen and the tool (compression testing) have been excluded mathematically $[11,12]$.

\section{Results and Discussion}

Material characterisation. The optical micrograph in Fig. 2a shows a mean grain size of $10 \mu \mathrm{m}$ for the magnesium alloy AZ31 $(\mathrm{Mg}-3 \mathrm{Al}-1 \mathrm{Zn}-0.3 \mathrm{Mn})$ in a recrystallized and twin-free state. The microstructure of the steel grade S235JR is characterised by a ferrite-pearlite structure, with a common rough share of $80 \%$ ferrite in the steel (Fig. 2b). The mean ferrite grain size was determined to be $12 \mu \mathrm{m}$ and the pearlite grain size $6 \mu \mathrm{m}$.

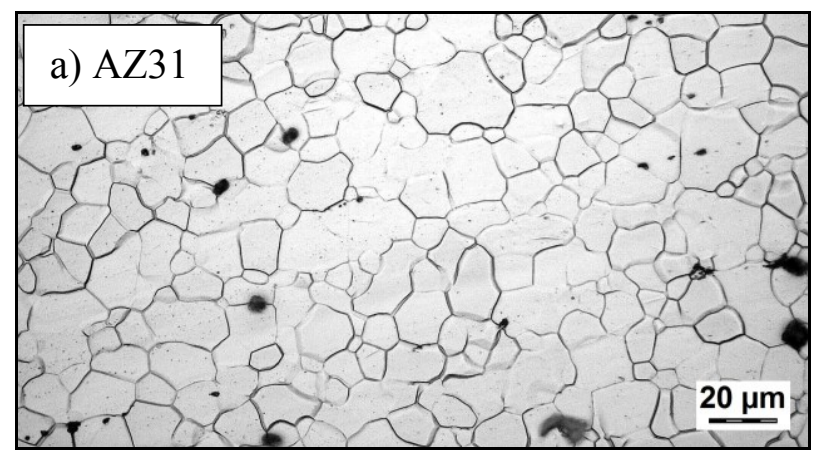

Fig. 2. Optical micrographs of the magnesium alloy AZ31 (a) and S235JR steel grade (b), as received

Tensile Testing. Representative flow curves obtained for the magnesium alloy and steel grade through tensile testing are shown in Fig. 3 as a function of temperature and initial strain rate. In the following, only flow curves of uniform elongation, hence only until necking, will be discussed. Necking of the tensile specimens changes the uniaxial stress state to a multiaxial stress state. At $250{ }^{\circ} \mathrm{C}$, a mean difference of approx. 5-10 MPa at maximum strain could be observed, when comparing constant traverse velocity to constant strain rate tests (Fig. 3a). In contrast, the flow curves determined at $350{ }^{\circ} \mathrm{C}$ show much lower yield stresses and no noteworthy difference in yield stresses at maximum strain for all initial strain rates (Fig. 3b). It can be presumed, that the theoretical difference in effective strain rate is less than $10 \%$ at maximum strain. Hence, the difference in yield stress is smaller than the possible error in measurement at $350{ }^{\circ} \mathrm{C}$. The lower yield stresses at $350{ }^{\circ} \mathrm{C}$ are due to temperature inversely dependant critical resolved shear stresses (CRSS) of non-basal slip systems in the hexagonal lattice structure. These affect the deformation behaviour strongly during hot forming of magnesium alloys as they are activated additionally to the low temperature dominant deformation mechanisms basal slip and mechanical twinning. Furthermore, the CRSS of non-basal slip systems is strain rate dependent, leading to higher yield stresses with higher strain rates. As reported by Barnett, the CRSS can be calculated as subordination of the Zener-Hollomon parameter, which entails temperature and strain rate [5, 13].

A similar conclusion can be drawn from the tensile flow curves of the S235JR steel grade, as the achieved maximum strains are too small to induce major yield stress differences, caused by strain rate divergence, at $1000^{\circ} \mathrm{C}$ in comparison to $900{ }^{\circ} \mathrm{C}$ (Fig. $3 \mathrm{c}$, d). As the lattice resistance to dislocation glide is strongly temperature dependent the yield stresses at $1000{ }^{\circ} \mathrm{C}$ are lower than at $900^{\circ} \mathrm{C}$. In order to move within a plane of atoms, dislocations need to overcome stresses, which decreases with rising temperature as a result of weaker atomic bond strength. At maximum strain without necking yield stress differences from $8 \mathrm{MPa}$ to $15 \mathrm{MPa}$ could be observed at $900{ }^{\circ} \mathrm{C}$. Multiple studies about bcc steels, as presented in [15], have reported the dependence of yield stress on strain rate. An increasing yield stress difference from $0.1 \mathrm{~s}^{-1}$ to $5 \mathrm{~s}^{-1}$ is attributed to excessive dislocation generation, therefore dislocation-dislocation interactions and enhanced work-hardening. 
Furthermore, it is understood that strain rate and temperature have a mutual influence on the yield stress. The work-hardenability is reduced as discontinuous glide and the overcoming of short range obstacles by dislocations is easier with rising temperature [16]. The responsiveness of metals to strain rate changes during hot deformation is also correlated to softening mechanisms such as dynamic recovery (DRV) or dynamic recrystallization (DRX). These are strain, strain rate and temperature dependent. The critical strain for the initiation of DRX, as discussed by Doherty et al., has not been reached at these small strains $\varphi \approx 0.1$ though [17]. The flow curves of both the magnesium alloy AZ31 and S235JR steel grade show a particular phenomenon, where the achieved maximum strain before necking, hence, the uniform elongation of the specimen, is recognisably larger at higher strain rates. This can be lead back to an increasing strain hardening coefficient at higher strain rates, inhibiting local necking $[7,18]$.
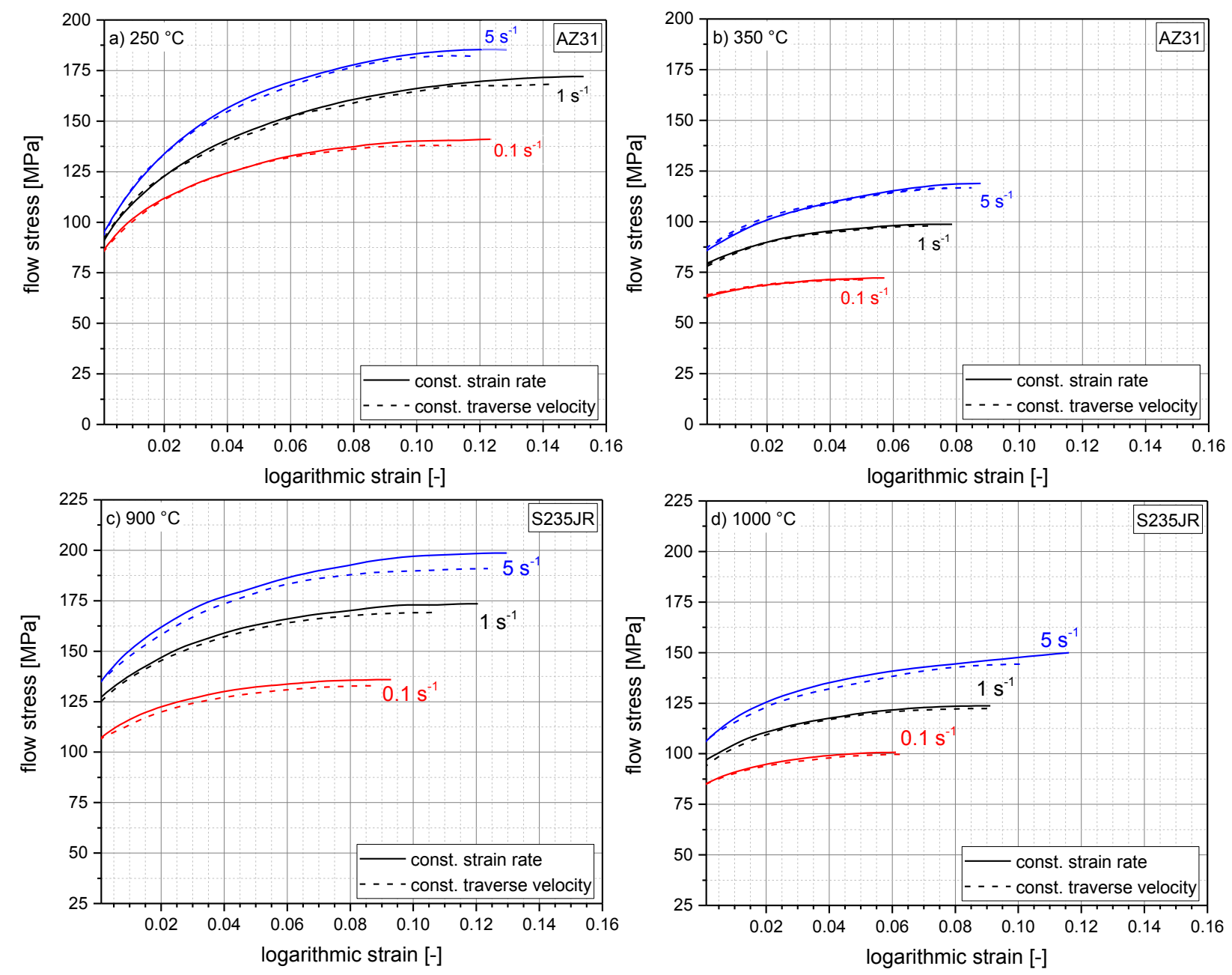

Fig. 3. Set of flow curves for magnesium alloy AZ31 (a: $250{ }^{\circ} \mathrm{C} ; \mathrm{b}: 350{ }^{\circ} \mathrm{C}$ ) and carbon steel grade S235JR (c: $900{ }^{\circ} \mathrm{C}$; d: $1000{ }^{\circ} \mathrm{C}$ ) acquired through tensile tests at strain rates as indicated

Compression Testing. As seen in the diagrams with representative flow curves in Fig. 4, much greater strains were achieved with compression specimens, resulting in an obvious discrepancy between deformation controlled and constant traverse velocities. Generally, it could be observed that the increased effective strain rate due to the constant traverse velocity results in higher yield stresses. The premature fracture of the AZ31 specimens at $250{ }^{\circ} \mathrm{C}$ is caused by the declined formability at high strain rates, causing the specimens to shear off, as seen in the left picture (Fig. 4a). Temperature and strain rate dependent CRSS of non-basal slip systems limit the deformation modes along the c-axis $[13,19]$. Due to limited slip systems, dislocation glide on basal planes and mechanical $\{10 \overline{1} 2\}$-twinning are the most dominant deformation mechanisms. As seen in the optical micrographs (Fig. 5a), presumably mechanical extension twinning, as they are quite 
broad compared to compression twins [20], occurring due to the limited number of activated slip systems at a testing temperature of $250{ }^{\circ} \mathrm{C}$ and $5 \mathrm{~s}^{-1}$ strain rate could be confirmed. The flow curves with $5 \mathrm{~s}^{-1}$ as well as $1 \mathrm{~s}^{-1}$ strain rate at $250^{\circ} \mathrm{C}$ are characterised by a concave shape typical for magnesium, as mechanical twinning initially contributes to deformation and following high levels of work hardening begin to increase the yield stress with progressing strain [21]. The magnesium specimens subjected to deformation at $0.1 \mathrm{~s}^{-1}$ strain rate and $250{ }^{\circ} \mathrm{C}$ are distinguished by a largely advanced DRX process, where the recrystallized grain is observed on both the boundaries of coarse grains and within primary grain areas (Fig. 5b). DRX is a diffusion controlled process, hence time and inversely strain rate dependent [17], and as a result softening in the flow curves of $0.1 \mathrm{~s}^{-1}$ and $250{ }^{\circ} \mathrm{C}$ is observed. An increase of the testing temperature from $250{ }^{\circ} \mathrm{C}$ to $350{ }^{\circ} \mathrm{C}$ at $0.1 \mathrm{~s}^{-1}$ strain rate intensifies the DRX leading to a complete dynamically recrystallized microstructure and grain growth.
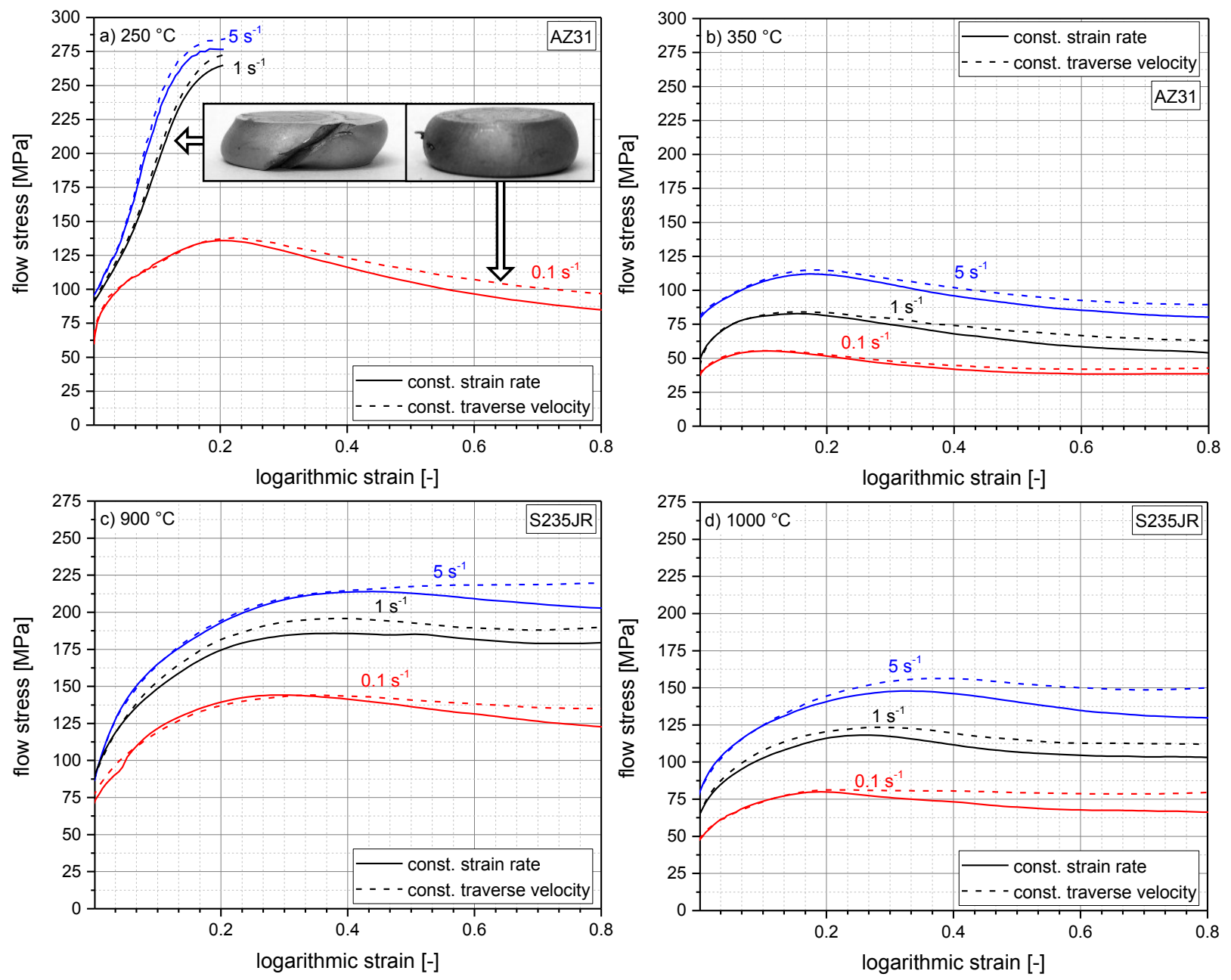

Fig. 4. Set of flow curves for magnesium alloy AZ31 (a: $250{ }^{\circ} \mathrm{C}$ - prematurely fractured specimen on the left and correctly deformed specimen on the right; b: $350{ }^{\circ} \mathrm{C}$ ) and steel grade S235JR (c: $900{ }^{\circ} \mathrm{C} ; \mathrm{d}: 1000{ }^{\circ} \mathrm{C}$ ) acquired through compression tests at strain rates as indicated

The rise in temperature also decreases the amount of mechanical twinning during deformation, as prismatic and pyramidal slip systems are more easily activated due to their decreased CRSS [13]. Flow curves determined at initial strain rates of $5 \mathrm{~s}^{-1}$ and $350{ }^{\circ} \mathrm{C}$ show an average increase of up to $15 \mathrm{MPa}$ in yield stress due to constant traverse velocities, compared to initial strain rates of $0.1 \mathrm{~s}^{-1}$ with a slightly lower difference (Fig. 4b). Here, the differences in the course of the flow curves with deformation controlled versus constant traverse velocity is lead back to strain rate dependant CRSS of non-basal slip systems and DRX processes.

The flow curves of the S235JR steel grade also show considerable differences when comparing constant strain rates to constant traverse velocities. Moreover, higher yield stresses were determined 
at $900{ }^{\circ} \mathrm{C}$ than at $1000{ }^{\circ} \mathrm{C}$, because thermally reduced lattice resistance enhance dislocation glide with rising temperature [14]. Overall, it can be said that the initial strain rates $5 \mathrm{~s}^{-1}$ show the most and $0.1 \mathrm{~s}^{-1}$ the least deviance in measured yield stress for both temperatures respectively (Fig. 4c, d). Higher work-hardening rates are caused by extensive dislocation development and dislocation pile-up at grain boundaries as high deformation rates have to be accommodated by increasing number of dislocations rather that dislocation glide and climb [16]. Large strains, as achieved by these compression specimens, also call for the thermally activated softening mechanisms DRV and DRX previously mentioned. All flow curves determined with the steel specimens show the typical shape as exemplified by [22]. After exceeding the critical strain, DRX and DRV initiate, reducing strain hardening, resulting in a steady-state of yield stress. The tested steel specimens indicate a microstructure with mostly completed DRX for initial strain rates $5 \mathrm{~s}^{-1}$ and full DRX for initial strain rates $0.1 \mathrm{~s}^{-1}$ and $1 \mathrm{~s}^{-1}$, with evenly distributed smaller grain sizes (Fig. 5c). As these thermally activated processes are diffusion controlled, increasing strain rates due to constant traverse velocity thus result in less time for thermal energy to overcome short range obstacles, explaining the incomplete DRX at $5 \mathrm{~s}^{-1}[16]$. The later commencement of DRX and DRV is also expressed by the shift of the flow curve peak to higher strains.
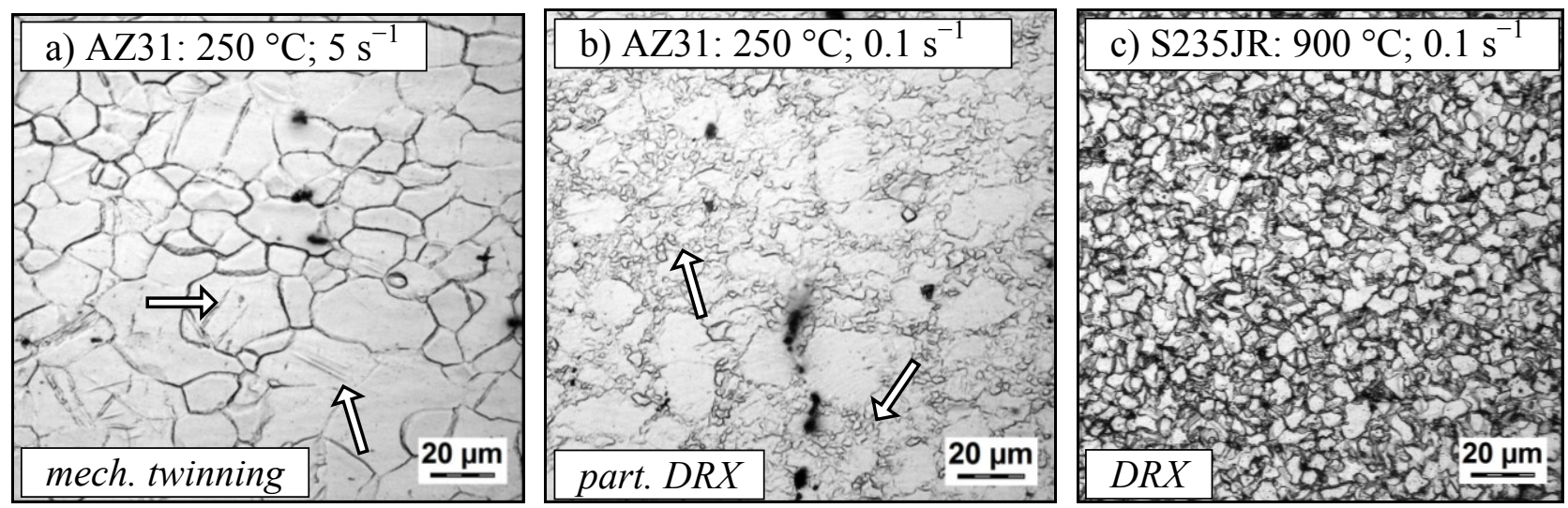

Fig. 5. Microstructure of the deformed magnesium alloy AZ31 specimen, indicating mechanical twinning (a) and partially dynamically recrystallized grain (b). Optical micrographs of fully recrystallized microstructure for the steel was observed (c)

\section{Summary and Conclusion}

The experimental effort consisted of uniaxial tensile and compression tests with AZ31 magnesium alloy and S235JR steel grade wire at elevated temperatures and strain rates from $0.1 \mathrm{~s}^{-1}$ to $5 \mathrm{~s}^{-1}$. Flow curves determined with deformation controlled versus constant traverse velocities were compared. Following points can be concluded:

(1) The change in effective strain rate during tensile and compression testing has shown a similar impact on the flow behaviour of the carbon steel grade S235JR and on the magnesium alloy AZ31.

(2) For the admission of flow curves with strains $\varphi>0.1$ deformation controlled strain rates are considered to be mandatory, because the effective strain rates deviate too far from the initial strain rates. Especially at high strains time dependent deformation mechanisms and thus the yield stresses, are influenced intensely. 


\section{References}

[1] E. Willbold, A. A. Kaya, R. A. Kaya, F. Beckmann, F. Witte, Corrosion of magnesium alloy AZ31 screws is dependent on the implantation site, Materials Science and Engineering: B 176 (2011) 1835-1840.

[2] X. Li, C. Guo, X. Liu, L. Liu, J. Bai, F. Xue, P. Lin, C. Chu, Impact behaviors of poly-lactic acid based biocomposite reinforced with unidirectional high-strength magnesium alloy wires, Progress in Natural Science: Materials International 24 (2014) 472-478.

[3] C.-L. Chu, X. Han, J. Bai, F. Xue, P.-K. Chu, Surface modification of biomedical magnesium alloy wires by micro-arc oxidation, Transactions of Nonferrous Metals Society of China 24 (2014) 1058-1064.

[4] B. L. Mordike, T. Ebert, Magnesium: Properties - applications - potential, Mater. Sci. Eng. A 302 (2001) 37-45.

[5] F. Berge, L. Krüger, H. Ouaziz, C. Ullrich, Influence of temperature and strain rate on the flow stress behavior of twin-roll cast, rolled and heat-treated AZ31 magnesium alloy, Transactions of Nonferrous Metals Society of China 25 (2015) 1-13.

[6] J. Qiao, Y. Wang, G.-D. Shi, High temperature tensile behaviors of extruded and rolled AZ31 Mg alloy, Trans. Nonferr. Met. Soc. 20 (2010) 540-544.

[7] M. Ma, H. Ding, Z.-Y. Tang, J.-W. Zhao, Z.-H. Jiang, G.-W. Fan, Effects of Temperature and Strain Rate on Flow Behavior and Microstructural Evolution of Super Duplex Stainless Steel under Hot Deformation, Journal of Iron and Steel Research, International 23 (2016) 244-252.

[8] T. Al-Samman, X. Li, S. G. Chowdhury, Orientation dependent slip and twinning during compression and tension of strongly textured magnesium AZ31 alloy, Mater. Sci. Eng. A 527 (2010) 3450-3463.

[9] F. Berge, L. Krüger, M. Ullmann, C. Krbetschek, R. Kawalla, Anisotropy of the mechanical properties of twin-roll cast, rolled and heat-treated AZ31 as a function of temperature and strain rate, Materials Today: Proceedings 2 (2015) 233-241.

[10]R. v. Mises, Mechanik der plastischen Formänderung von Kristallen, Z. angew. Math. Mech. 8 (1928) 161-185.

[11]K. Pöhlandt, Materials testing for the metal forming industry, Springer-Verlag, 1989.

[12]M. Ullmann, Rekristallisationsverhalten von geglühtem AZ31-Gießwalzband beim Warmwalzen. Dissertation, Freiberg, 2014.

[13]M. R. Barnett, A Taylor model based description of the proof stress of magnesium AZ31 during hot working, Metall. Mat. Trans. A 34 (2003) 1799-1806.

[14]A. Seeger, The mechanism of glide and work hardening in face-centered cubic and hexagonal close-packed metals, in: J.C. Fisher (Ed.), Dislocation and mechanical properties of crystals, John Wiley, New York, 1957, pp. 243-329.

[15]P. J. Geng, W. G. Li, X. H. Zhang, J. X. Shao, Y. Deng, J. Z. Ma, H. B. Kou, A new temperature and strain rate dependent yielding model for iron-based body-centered-cubic metallic materials, Journal of Alloys and Compounds 684 (2016) 116-119.

[16]Z. Xu, F. Huang, Plastic behavior and constitutive modeling of armor steel over wide temperature and strain rate ranges, Acta Mechanica Solida Sinica 25 (2012) 598-608. 
[17]R. D. Doherty, D. A. Hughes, F. J. Humphreys, J. J. Jonas, D. Juul Jensen, M. E. Kassner, W. E. King, T. R. McNelley, H. J. McQueen, A. D. Rollett, Current issues in recrystallization: a review, Mater. Sci. Eng. A 238 (1997) 219-274.

[18]F. Berge, Temperatur- und dehnratenabhängiges Werkstoffverhalten von warmgewalztem und abschlussgeglühtem AZ31-Gießwalzband als Funktion des Spannungszustandes. Dissertation, Freiberg, 2016.

[19]M. H. Yoo, Slip, twinning, and fracture in hexagonal close-packed metals, Metall. Trans. A 12 (1981) 409-418.

[20]N. V. Dudamell, I. Ulacia, F. Gálvez, S. Yi, J. Bohlen, D. Letzig, I. Hurtado, M. T. PérezPrado, Twinning and grain subdivision during dynamic deformation of a Mg AZ31 sheet alloy at room temperature, Acta Mater. 59 (2011) 6949-6962.

[21]A. Jain, S. R. Agnew, Measuring the temperature dependence of the flow surface of magnesium alloy sheet, Magnesium Technology (2005) 71-76.

[22]M. Graf, M. Ullmann, G. Korpala, R. Kawalla, Materialkennwerte als Basis für die numerische Simulation von Warmumformprozessen, Verformungskundliches Kolloquium Proceedings 22 (2013) 49-55. 